\title{
ANALISIS KANDUNGAN BORAKS PADA BAKSO YANG DIJUAL DI ANDUONOHU KOTA KENDARI SULAWESI TENGGARA
}

\author{
Sitti Rachmi Misbah, Satya Darmayani, Narti Nasir \\ Jurusan Analis Kesehatan Poltekkes Kemenkes Kendari
}

\begin{abstract}
Fast food consumption today has become a habit of eating for the people in Indonesia. One of the popular fast food is meatballs, but nowadays often found the use of non-food additives in the meatballs, namely borax. The Indonesian Republic Food and Drug Administration has detected the abusive use of borax on food derived from various regions of Indonesia. Borax is a chemical compound derived from heavy metals, namely Boron and commonly used as an anti-fungal and wood preservative. This study aimed to determine the content of borax on meatballs that was sold in Anduonohu, Kendari City of Southeast Sulawesi. Type of research using total sampling conducted by observational descriptive by the qualitative method that was using the method of centrifugation and dry ash processing. The results showed that from 24 samples of meatballs located in Anduonohu, Kendari City, it was proven that none of the meatballs contained borax which could endanger the consumer's health which was marked by no change of green color when heated on the flame. Based on the results of the analysis can be concluded that all sellers of meatballs located in Anduonohu, Kendari City have the knowledge and good attitude. Knowledge and attitude level is one important factor in order to avoid pollution of toxin material. Meatball processing method in Anduonohu, Kendari City has fulfilled the requirement of Indonesian Republic Health Minister Regulation in 2015, Number: 722/Menkes/Per /IX/2015 about food, so people do not have to worry about consuming meatballs located in Anduonohu, Kendari City.
\end{abstract}

\section{Keywords: Borax, Meatball, Method of Centrifugation, Dry Ash Processing}

\section{PENDAHULUAN}

Codex Committee on Food Additives and Contaminants (CCFAC) menyatakan bahwa permasalahan pangan di Indonesia sangat kompleks mulai dari masalah penggunaan bahan tambahan pangan (BTP) yang kini tidak memperhatikan kesehatan konsumen, pengolahan makanan yang kurang sehat, hingga masalah kehalalan bahan pangan bagi umat beragama seperti Islam. Banyak produsen yang masih keliru dalam penggunaan BTP dikarenakan beragam alasan, mulai dari alas an ketidaktahuan, kesalahan dalam memahami fungsi dari BTP, namun tidak sedikit pula karena unsur kesengajaan dengan alas an lebih mudah, lebih murah, dan lainnya. Kekeliruan dalam penggunaan BTP diantaranya penggunaan bahan pewarna tekstil dalam pangan, penggunaan boraks dan formalin, penggunaan pengawet lainnya yang tidak memenuhi standar keamanan pangan (Faradila dkk, 2014). BPOM RI (2009) mendeteksi masih banyaknya penyalahgunaan penggunaan boraks dan formalin pada bahan pangan yang diperoleh dari berbagai daerah di Indonesia.

Data Badan Pengawas Obat dan Makanan (BPOM) menunjukkan bahwa sepanjang tahun 2012, insiden keracunan akibat mengkonsumsi makanan menduduki posisi paling tinggi yaitu $66,7 \%$ dibandingkan dengan keracunan akibat penyebab lain misalnya obat, kosmetika dan lain-lain. Salah satu penyebab keracunan makanan adalah adanya cemaran kimia dalam makanan tersebut seperti boraks, formalin dan rhodamin-B, juga diketahui 2,93\% sampel makanan jajanan pada anak sekolah mengandung boraks, $1,34 \%$ mengandung formalin dan $1,02 \%$ mengandung rhodamin-B. Akumulasi bahan-bahan tersebut di dalam tubuh dapat berdampak negatif bagi kesehatan.

Efek negatif toksisitas boraks pada manusia masih dapat ditoleransi seperti nafsu makan yang menurun, gangguan sistem pencernaan, gangguan pernafasan gangguan sistem saraf pusat ringan seperti halnya mudah bingung, anemia, serta kerontokan pada rambut. Namun bila dosis toksin telah mencapai atau bahkan melebihi batas maksimal maka akan mengakibatkan dampak yang fatal, mulai dari muntah-muntah, diare, sesak nafas, kram perut dan nyeri perut bagian atas (epigastrik), mual, lemas, pendarahan gastroentritis disertai muntah darah serta sakit kepala yang hebat. Boraks tidak hanya diserap melalui pencernaan 
namun juga dapat diserap melalui kulit (Paratmanitya \& Aprilia 2016).

Hikmawati (2010) dalam penelitiannya tentang studi kandungan boraks pada makanan yang beredar di kota Medan, memperoleh hasil dari 12 sampel bakso $100 \%$ positif mengandung boraks, dari 30 sampel mie diperoleh $84 \%$ positif mengandung boraks, dan dari 9 sampel lontong diperoleh $11,1 \%$ positif mengandung boraks. Penelitian lain yang dilakukan oleh Panjaitan (2010) yang meneliti kandungan boraks pada bakso di Kota Medan, menyimpulkan bahwa $80 \%$ dari sampel yang diperiksa ternyata mengandung boraks ( 8 dari 10 sampel) dengan kadar boraks antara 0,08\%0,29\%. Nurkholidah, dkk (2012) menyatakan dari 17 pedagang bakso tusuk yang berjualan di lingkungan Sekolah Dasar di Kecamatan Bangkinang terungkap bahwa hampir seluruh pedagang menggunakan boraks pada produk bakso tusuk dengan kandungan tertinggi 2,32 $\mathrm{mg} / \mathrm{g}$ sampel. Namun demikian tidak semua daerah dan produsen menggunakan boraks sebagai pengawet makanan dan pengenyal, ini dibuktikan dari hasil penelitian Triastuti,dkk (2013) pemeriksaan kandungan boraks pada tahu yang diproduksi di Kota Manado dengan menggunakan metode easy test boraks, terbukti tidak mengandung boraks.

Pada dasarnya terdapat beberapa alas an produsen makanan menambahkan BTP dalam produk mereka. Misalnya, pengawetan akan menjadikan makanan dapat disimpan berhari-hari, bahkan berbulan-bulan, dan hal tersebut menguntungkan pedagang. Penggunaan BTP ini juga berfungsi sebagai daya tarik makanan itu sendiri sehingga menambah minat konsumen. Selain itu juga kedua bahan ini lebih mudah didapat dan harganya yang relatif murah di bandingkan bahan pengawet yang tidak berbahaya bagi kesehatan (Pujiastuti dkk, 2002).

Hasil laporan harian BPOM Provinsi Sulawesi Tenggara tahun 2016 menyatakan dari 1263 sampel makanan yang di uji, diperoleh $(0.07 \%)$ mengandung formalin, $(1,10 \%)$ mengandung rhodamin-B dan (0,15\%) mengandung boraks. Untuk Kota Kendari menurut BPOM tahun 2016 dari hasil tes uji laboratorium ditemukan adanya beberapa pengusaha makanan jajanan tahu dan bakso yang menggunakan bahan pengawet boraks, walaupun presentase kejadian khususnya di Kota Kendari cukup rendah, namun jika tidak diantisipasi lebih lanjut maka akan menyebabkan faktor resiko yang cukup besar (BPOM, 2016).

Pengujian makanan yang mengandung boraks dibagi menjadi dua yaitu uji kuantitatif dan uji kualitatif. Uji kuantitatif menggunakan metode titrimetri sedangkan uji kualitatif terdiri dari beberapa metode yaitu metode sentrifugasi, pengabuan dan easy test boraks. Uji kualitatif pada sampel makanan merupakan metode yang paling umum digunakan karena pengerjaannya tidak begitu sulit, murah, dan waktu pengerjaan yang tidak terlalu lama (Rohman \& Sumantri 2007).

Dari beberapa kecamatan yang berada di Kota Kendari, bakso hampir dijual di seluruh wilayah Kota Kendari. Dari hasil survei di Anduonohu didapatkan bakso dijual pada 24 warung bakso permanen dan belum termasuk yang dijual oleh pedagang kaki lima dengan rata-rata jumlah kunjungan 25 orang dalam sehari. Oleh karena penggunaan boraks sangat berbahaya maka perlu adanya penelitian tentang analisis kandungan boraks pada bakso yang di jual di Anduonohu Kota Kendari Sulawesi Tenggara untuk menjamin kualitas makanan yang dikonsumsi masyarakat.

\section{METODE PENELITIAN Jenis Penelitian}

Penelitian ini dilakukan adalah secara deskriptif observasional dengan cara kualitatif yaitu menggunakan metode sentrifugasi dan metode pengabuan.

1. Metode Sentrifugasi

Bakso yang telah diblender kurang lebih 10 gr dimasukkan dalam sentrifugasi (diputar selama 5 menit dengan kecepatan 3000 rpm) sehingga diperoleh supernatan, supernatan diambil sebanyak 3 mL kemudian masukkan kedalam tabung reaksi lalu ditambahkan $\mathrm{H}_{2} \mathrm{SO}_{4}$ pekat 10 tetes dan alkohol $70 \%$ sebanyak $2 \mathrm{~mL}$ Dipanaskan diatas lampu spritus, apabila nyala api berwarna hijau maka bahan makanan tersebut positif mengandung boraks.

2. Metode Pengabuan

Bakso yang telah diblender kurang lebih 10 gr dimasukkan ke dalam tanur hingga menjadi abu selama 2 jam pada suhu $500^{\circ} \mathrm{C}$, lalu abu dimasukkan kedalam tabung reaksi dan ditambahkan $\mathrm{H}_{2} \mathrm{SO}_{4}$ pekat 10 tetes dan Alkohol $70 \%$ sebanyak 2 Ml. Dipanaskan diatas lampu spritus, apabila dibakar nyala 
api berwarna hijau maka bahan makanan tersebut positif mengandung boraks.

\section{Waktu dan Lokasi Penelitian}

Penelitian ini dilaksanakan pada Bulan Juli Tahun 2017 di Laboratorium Analis Kesehatan Politeknik Kesehatan Kendari.

\section{Sampel}

Penelitian ini menggunakan bakso sebagai sampel untuk dilakukan pemeriksaan dan dianalisis. Bakso yang diambil yaitu bakso yang dijual di sekitar wilayah Anduonohu Kota Kendari Sulawesi Tenggara, dari 24 penjual bakso.

\section{Teknik Pengumpulan Data}

Pengumpulan data dilakukan secara deskriptif yaitu mencatat hasil pemeriksaan laboratorium berupa uji kualitatif kandungan boraks.

\section{Penyajian Data}

Data yang diperoleh dari hasil uji laboratorium kemudian diolah dan di sajikan dalam bentuk table serta diuraikan dalam bentuk narasi.

\section{HASIL PENELITIAN}

Pemeriksaan kandungan boraks dilakukan pada 24 sampel bakso yang dijual di Anduonohu Kota Kendari Sulawesi Tenggara. Sampel yang diperoleh dari pedagang bakso kemudian dianalisis di Laboratorium Analis Kesehatan Politeknik Kesehatan Kendari menggunakan analisa kualitatif dengan menggunakan metode sentrifugasi dan metode pengabuan untuk mengetahui ada atau tidaknya kandungan boraks pada bakso

\section{Tabel 1. Distribusi Pemeriksaan Kandungan Boraks Menggunakan Metode Sentrifugasi dan Metode Pengabuan}

\begin{tabular}{ccccc}
\hline Hasil & \multicolumn{2}{c}{ Sentrifugasi } & \multicolumn{2}{c}{ Pengabuan } \\
\cline { 2 - 5 } Penelitian & $\mathrm{n}$ & $\%$ & $\mathrm{n}$ & $\%$ \\
\hline Positif & 0 & 0 & 0 & 0 \\
Negatif & 100 & 100 & 100 & 100 \\
\hline Total & 24 & 100 & 24 & 100 \\
\hline
\end{tabular}

Berdasarkan tabel 1, hasil penelitian menunjukkan bahwa dari 24 sampel yang di analisis menggunakan metode sentrifugasi dan metode pengabuan tidak satupun ditemukan adanya kandungan boraks pada 24 sampel bakso, yang ditandai dengan tidak terjadi perubahan warna hijau pada saat dipanaskan diatas nyala api maka bahan makanan tersebut tidak mengandung boraks.

\section{PEMBAHASAN}

Analisa kandungan boraks pada bakso yang diambil dari 24 pedagang bakso yang berbeda-beda yang tersebar di Kelurahan Anduonohu Kota Kendari Sulawesi Tenggara dengan menggunakan metode sentrifugasi dan metode pengabuan, hasil penelitian menunjukkan bahwa dari 24 sampel tidak satupun bakso yang dijual mengandung boraks yang dapat membahayakan kesehatan manusia. Ini menandakan bahwa bakso yang berada di Kelurahan Anduonohu Kota Kendari Sulawesi Tenggara sebagian besar dalam kategori yang baik sehingga bakso aman untuk dikomsumsi.

Penelitian ini sejalan dengan penelitian yang dilakukan oleh Tubagus, dkk (2013) tentang identifikasi kandungan Boraks pada jajanan bakso di Kota Manado dimana sampel diidentifikasi mengunakan metode Uji nyala dan metode Uji warna dengan kertas turmerik. Hasil penelitian percobaan identifikasi boraks dalam sampel bakso dengan reaksi Uji nyala dan Uji warna diketahui bahwa semua sampel bakso yang diuji tidak mengandung bahan pengawet berbahaya, yaitu boraks. Sehingga tidak diadakan penelitian lanjutan dengan Spektrofotometri UV-Vis.

Berdasarkan pasal 10 UU No.7 Tahun 2015 tentang pangan juga disebutkan bahwa setiap orang yang memproduksi pangan untuk diedarkan dilarang menggunakan bahan apa pun sebagai bahan tambahan pangan yang dinyatakan terlarang atau melampaui ambang batas maksimal yang ditetapkan. Hal ini menunjukkan bahwa masyarakat wajib ikut serta dalam pengawasan terhadap keamanan pangan mulai dari sumbernya sampai dikonsumsi oleh masyarakat. Hasil penelitian menunjukkan bahwa metode pengolahan bakso di Anduonohu Kota Kendari sudah memenuhi syarat Peraturan Menteri Kesehatan, 2015.RI No.722/Menkes/Per/IX/15 tentang pangan, sehingga masyarakat tidak perlu khawatir untuk mengkomsumsi bakso yang berada di Kelurahan Anduonohu Kota Kendari kerena telah terbukti bahwa bakso tersebut tidak mengandung boraks.

Berdasarkan hasil analisis di atas maka dapat dikatakan bahwa semua penjual bakso 
yang berada di Anduonohu Kota Kendari memiliki pengetahuan dan sikap yang baik. Tingkat pengetahuan dan sikap merupakan salah satu faktor penting agar tidak terjadi pencemaran bahan toksin seperti boraks pada bahan makanan yang diperjual belikan. Menurut Sugiyono (2004), nilai koefisien korelasi antara $0,40-0,599$ dapat menginterpretasikan tingkat hubungan sedang antara 2 variabel. Dalam hal ini ada hubungan sedang antara tingkat pendidikan pedagang dengan pengetahuan terhadap penggunaan bahan tambahan pangan. Rata-rata pedagang bakso yang berada di Kelurahan Anduonohu kemungkinan telah mengetahui bahaya dari penggunaan bahan toksin seperti formalin atau boraks. Asam borat merupakan racun yang apabila masuk ke dalam tubuh, dapat menyebabkan mual, muntah, diare, sakit perut, penyakit kulit, kerusakan ginjal, dan bahkan kematian. Sugiyatmi (2007) menyatakan bahwa boraks merupakan turunan logam berat Boron (B) yang berbahaya dan beracun. Keadaan ini apabila dibiarkan akan berdampak kurang baik terhadap kondisi kesehatan masyarakat.

\section{KESIMPULAN DAN SARAN}

\section{Kesimpulan}

Dari hasil analisis kandungan boraks dengan menggunakan metode sentrifugasi dan metode pengabuan pada 24 sampel bakso yang berasal dari pedagang berbeda-beda yang tersebar di Kelurahan Anduonohu, sama-sama di peroleh hasil bahwa tidak satupun bakso yang mengandung boraks, sehingga masyarakat tidak perlu khawatir untuk mengkomsumsi bakso yang berada di Kelurahan Anduonohu Kota Kendari kerena telah terbukti bahwa bakso tersebut tidak mengandung boraks.

\section{Saran}

Diharapkan kepada pedagang bakso untuk tetap mempertahankan syarat mutu atau kualitas bakso agar tidak terpengaruh terhadap penggunaan bahan kimia lain yang dapat merugikan pedagang maupun masyarakat yang mengkomsumsi. Serta pada peneliti selanjutnya diharapkan memperluas lokasi penelitian yang mencakup seluruh wilayah Kota Kendari dan diharapkan juga untuk menganalisis kandungan boraks dan formalin pada makanan lain seperti tahu, mie basah, kerupuk, dan lontong.

\section{DAFTAR PUSTAKA}

BPOM RI. (2009). Bahaya rhodamin B sebagai pewarna pada makanan. Jakarta: BPOM RI.

Depkes R.I dan Dirjen POM. (2007). Peraturan Menteri Kesehatan RI Nomor722/Menkes/Per/IX/1988 Tentang Bahan Tambahan Makanan. Jakarta: DepKes RI.

Faradila. Alioes, Y. Elmatris. (2014) . Identifikasi Formalin pada Bakso yang Dijual pada Beberapa Tempat di Kota Padang. Jurnal Kesehatan Andalas. Vol. 3 (2). Hal : 156-158.

Hikmawati, S. (2010). Studi Kandungan Boraks pada makanan yang beredar di kota Medan tahun 2010. Medan: repository.

Nurkholidah, Ilza, M.,Zose, C. (2012). Analisis Kandungan Boraks Pada Jajanan Bakso Tusuk di Sekolah Dasar di Kecamatan Bangkinang Kabupaten Kampar. J. Ilmu Lingkung-an. Vol. 6 (2). Hal : 134-145.

Panjaitan, L. (2010). Pemeriksaan Dan Penetapan Kadar Boraks Dalam Bakso Di Kota Madya Medan. Medan: USU.

Paratmanitya, Y.. Aprilia V. (2016). Kandungan Bahan Tambahan Pangan Berbahaya Pada Makanan Jajanan Anak Sekolah Dasar di Kabupaten Bantul. Jurnal Gizi Dan Dietetik Indonesia. Vol. 4 (1). Hal : 49-55. Program Studi S1 Ilmu Gizi, Fakultas Ilmu-Ilmu Kesehatan, Universitas Alma Ata Yogyakarta.

Peraturan Menteri Kesehatan. (2015). RI No. 722/Menkes/Per/IX/2015.

Pujiastuti, Z., Sulistiyani., Nurjazuli. (2002). Beberapa Faktor Yang Berhubungan Dengan Pemakaian Bahan Tambahan Pangan (BTP) Pada Produk Kerupuk Di Kecamatan Kaliwangu, Kabupaten Kendal. Jurnal Kesehatan Lingkungan Indonesia. Vol. 1 (2). Hal : 61-65.

Rohman, A dan Sumantri. (2007). Analisis Makanan. Bandung: Institut Teknologi Bandung.

Sugiyatmi, Sri. (2007). Analisis Faktor-Faktor Risiko Pencemaran Bahan Toksik Boraks Dan Pewarna Pada Makanan Jajanan Tradisional Yang dijual Di Pasar-Pasar Kota Semarang Tahun 2007. Tesis. Semarang:Universitas Diponegoro.

Sugiyono. (2004). Metode Penelitian Bisnis. Alfabeta. Bandung. 
Triastuti, E., Fatimalati., Runtuwene, M.R.J. (2013). Analisis Boraks pada Tahu yang Diproduksi di Kota Manado. Manado: Pharmacon. Vol. 2 (1). Hal : 69-74.

Tubagus, I., Citraningtyas, G., Fatimawali. (2013). Identifkasi dan Penetapan Kadar
Boraks Dalam Bakso Jajanan Di Kota Manado. Jurnal Ilmiah FarmasiUNSRAT. Vol. 2 (4). Hal: 142-148. 